\title{
The Strategies and Methods on Small Towns Ecological Planning in the New Pattern Urbanization Construction
}

\author{
DingQing Zhang ${ }^{1, a^{*}}$, WanWan Shao ${ }^{2, b}$ and LiZhe $X^{3, c}$ \\ ${ }^{1}$ School of Human Settlements and Civil Engineering, Xi'an Jiaotong University, P.R. China \\ ${ }^{2}$ College of Fine and Applied Art, University of Illinois at Urbana-Champaign, U.S.A \\ ${ }^{3}$ School of Human Settlements and Civil Engineering, Xi'an Jiaotong University, P.R. China \\ azhangdq@mail.xjtu.edu.cn, b476697306@qq.com, c381102844@qq.com
}

Keywords: New pattern urbanization construction; Ecological planning; Small town

Abstract. For the lack of ecological planning and the weakness of ecological construction in the development of small towns, based on the idea of ecological civilization advocated in the new pattern urbanization, combined with the conceptual planning in Qindu, Hu County, the strategies and methods of ecological development in the small town is explored. It proposed to take advantage of the natural and cultural resources of ancient town, and integrate ecological sustainability thinking into the planning and construction of town at all levels. On the basis of the overall ecological pattern to maintain ecological security of the town, the ecological function zoning is determined, the method of river ecosystem protection and restoration is put forward, and the industry development and function layout is guided, in order to promote harmonious development of urban-rural society, economy and environment.

\section{Introduction}

The development of small towns plays an important role in the construction of new pattern urbanization, which is the key to promote eco-social development and implement co-ordination of urban and rural areas. Traditional development model is economically oriented at the expense of the environment, which leads to the lag of small towns ecological planning. In view of the concept of ecological civilization emphasized in new pattern urbanization, strategies and methods for ecological development of small towns is worthy of discussion in the practice of new pattern urbanization.

\section{Background of Qindu Planning}

\section{Development Advantages}

Geographical Advantages. The town of Qindu (the Qin town), with a total area of $49.8 \mathrm{~km}^{2}$ and total population of 53,000, located in Hu County east gate (22km away from Xi'an city), is the nearest town to Xi'an (refer with: Fig. 1). According to the Three Sub-central Cities Planning in Xi'an Metropolitan Area (2012) introduced by Xi'an government, Hu County will become one of sub-central city of Xi'an. It is obvious that favorable geographical conditions bring the Qin town great opportunities for development. 


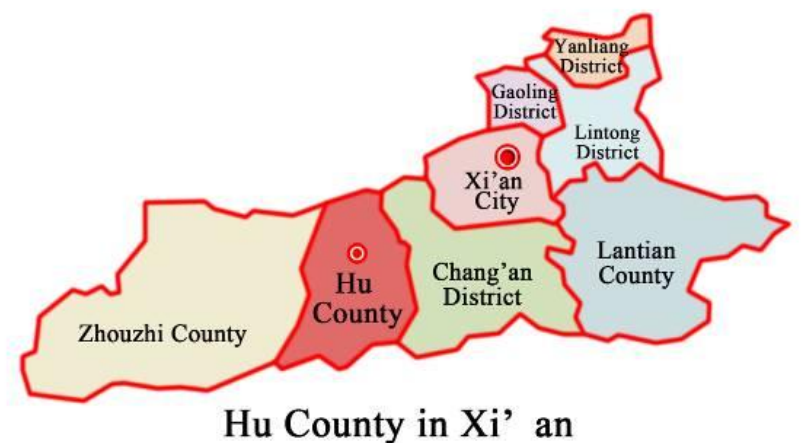

$\mathrm{Hu}$ County in Xi' an

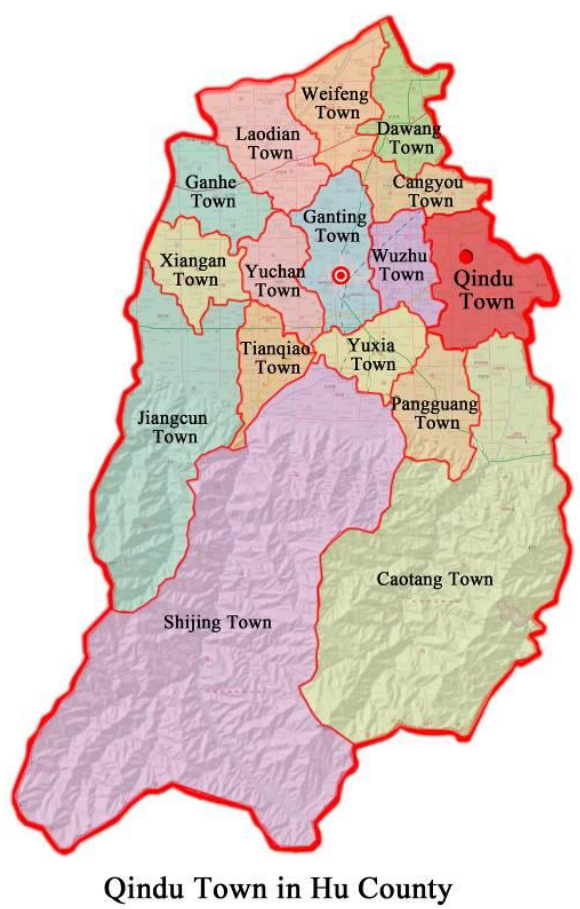

Qindu Town in Hu County

Fig. 1 Location of Qindu

Pleasant Natural Environment. Qin town is located in the Guanzhong Plain, north of Qinling Mountains, west of Fenghe River, in a warm-humid continental monsoon climate. There are Fenghe River and Canglong River flowing through, which makes abundant groundwater resources and fertile soil. Qin town is a traditional agricultural town, rich in agricultural products. Blessed with abundant water, mild climate, natural resources and agricultural advantages, Qin town has basic conditions for ecological development.

Historical and Cultural Heritage. Qin town is a famous historic town in Guanzhong Plain, used to be the capital of the Western Zhou Dynasty. Besides, it was the gathering place of traffic and trade, forming a unique layout as an ancient town with deep historical and cultural heritage. The town retains old street, old stores, South Gate, Guandi Temple, city wall ruins and other historic sites. Cold noodle of Qin town is a famous local snack included in the first batch of Intangible Cultural Heritage List of Shaanxi Province.

Transport Facilities. The Xihu highway and the Xihan expressway cross Qin town, which makes it convenient to get to Xi'an. The Xihu highway is the main road across the town, determined as the main axis of space development of Hu County in the city system planning. In addition, according to the Xi'an urban rail transit planning, the under-planning metro line15 has two stations located in Qin town along the Xihu highway. Xixian loop expressway (still under-planning) crosses the field of Qin town in northwest-southeast direction (refer with: Fig. 2). 


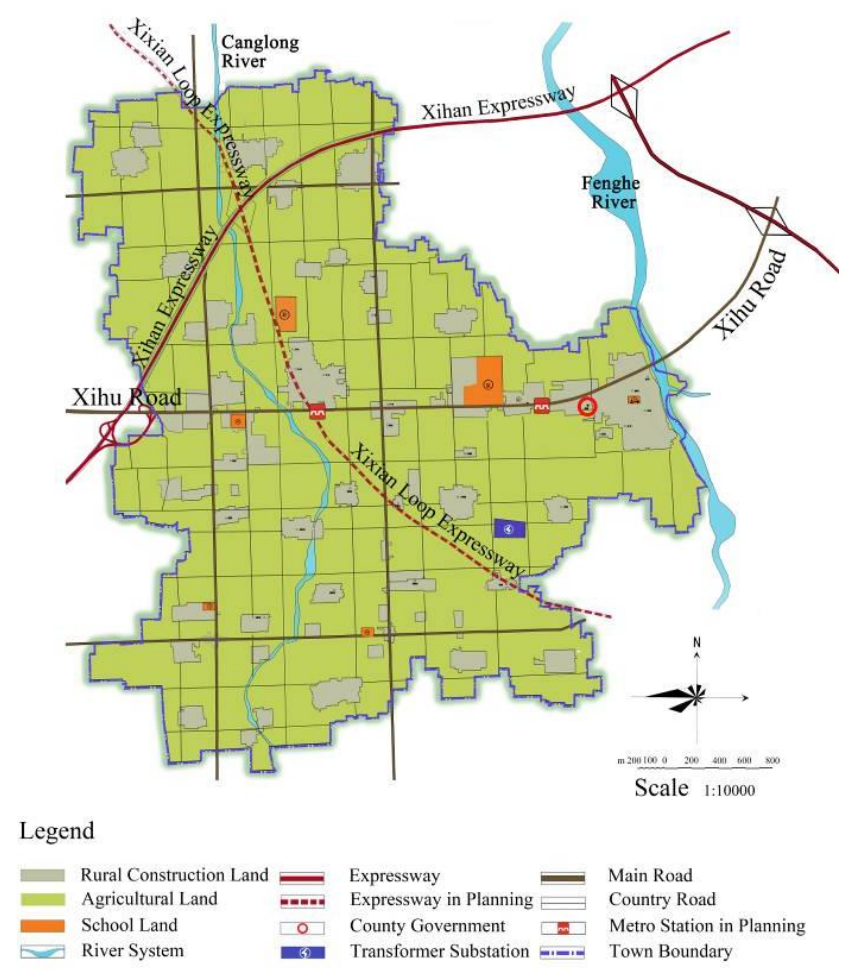

Fig. 2 Status quo of Qin town

\section{The Main Problems with Town Development}

Lack of Motivation. The development of the agricultural modernization level is not high in Qin town currently and it lacks industry chain. Scattered small township enterprises lack of modern technology industries, make it difficult to form clusters advantage. The underdeveloped tertiary industry only shares small proportion of GDP.

Imperfect Function. Qin town is basically a traditional small town with single function and inadequate economic development. Scattered villages in the town are in small scale. Low-level public services need to be improved.

Lack of Improvement of Environment. The use of Fenghe River coastal land lacks scientific planning, resulting in the degradation of the wetland. The inefficient pollution control technology in township enterprises results in the increasingly prominent problems of environmental pollution and ecologicaldestruction, restricting the sustainable development of the town.

Lack of Protection for Historical and Cultural Heritage. The old street in Qin town has not been effectively protected. Old-fashioned brick shops and houses have been damaged severely. City wall ruins and other sites are also facing destruction. The style of ancient town is shrinking with historical and cultural characteristics gradually disappearing.

The Upper Guiding Planning. As a sub-central city of Xi'an, the Hu County is positioned as a high-tech industrial zone, a Qinling Mountains tourism service base and a livable city. It is planned to form a high-tech industry-led industrial layout, pillared with energy industry, machinery manufacturing and agricultural processing industry. At the same time, construction of key projects and the industrial parks shall be promoted. As the joint of Xi'an City and Hu County, the new pattern urbanization of Qin town should take this as the guide, carry out renovation of traditional agriculture to industrialization and eco-development, as well as construct industrial parks and introduce new technology industries. Meanwhile, it is important to actively protect and make use of ecological and cultural resources, keep the eco- health of the town, and inherit its cultural characteristics. 


\section{Planning Conception and Structural Layout}

Planning Goals. To give full play to the advantages of the ancient town, the planning should be guided by ecological concept, based on historical and cultural features, supported by modern agriculture and modern science and technology industries, ensured by business services and livability. Aimed at the exploration for development path of new pattern urbanization, Qin town is intent to be built into a model town with ecological environment quality, rich history and culture, set of ecological agriculture, modern industry, trade and tourism, culture and leisure as a whole.

Planning Concepts. By taking consideration of ecological sustainability into all aspects of planning and construction, advocating protection and restoration of the ecological environment, promoting the development of eco-industries, the pattern of combination of river, land, town and park will be formed.

The spatial pattern of ancient town should be carefully protected, and the value of historical and cultural heritage will be promoted. By proper use of historical and cultural resources, the local tourism will be promoted which is conducive to local economy.

Pillared by modern agriculture and modern industry, a new urban-rural relationship would be formed with improvement of infrastructure and public services, and aggregation of commerce function.

Planning Structure. Combined with the existing advantages of Qin town and the upper planning, an energetic layout will be established, showing the overall pattern of "one center, two axes, two belts, three zones" (refer with: Fig. 3).

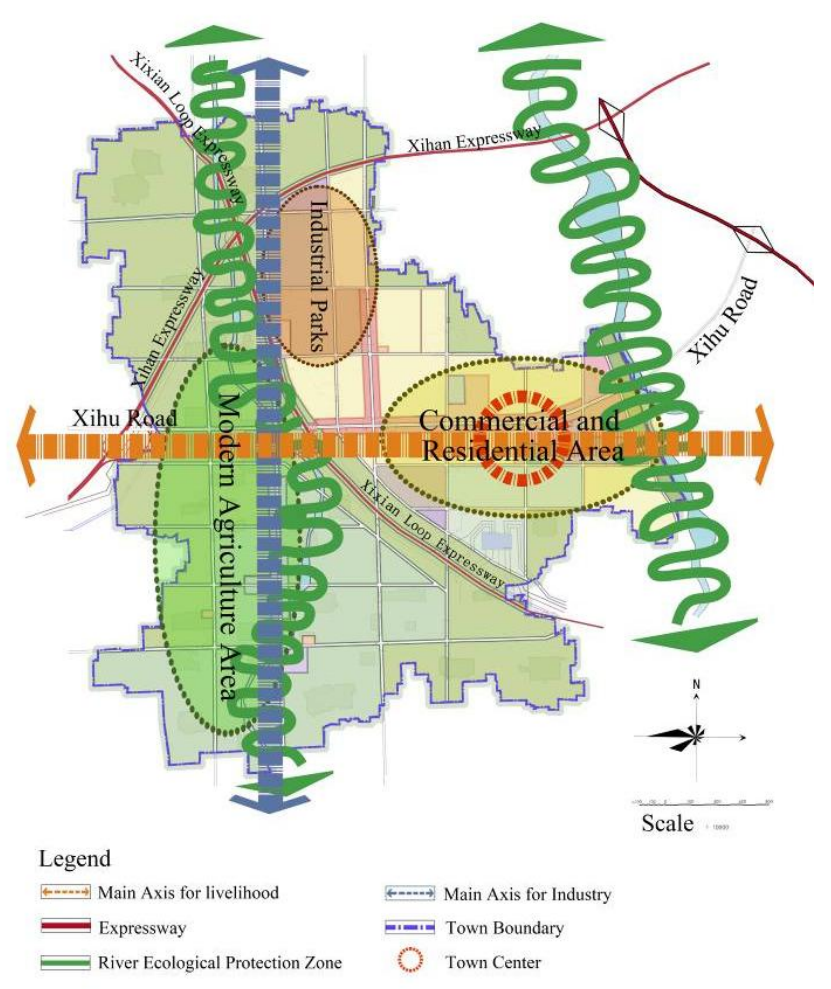

Fig.3 The overall structure of the Qin town planning

"One center": Relying on the convenient transportation of Xi'an subway planning and the mixed land use guided by public transport, a central commercial zone will be formed.

"Two axes": Along the Xihu road as the east-west axis, a living and commercial area should be developed. For another, along the planning main road as the north-south axis, agriculture area and industry area should be formed.

"Two belts": Combining the river remediation and shoreline planning, there should be a riverside landscape belt along Fenghe River. For another, a vernacular landscape belt should be created along the Canglong River. 
"Three zones": Divided by the under-planning Xixian loop expressway, the east is mainly construction land for commercial \& residential function and industrial parks, and the west is non-construction land as a modern agricultural zone.

\section{Strategies and Methods for Ecological Planning}

Overall Ecological Pattem. Based on the perspective of landscape ecology, a landscape pattern of matrix-patch-corridor should be improved: protecting the farmland resources to form a green matrix of town, developing varied public green space to form green mosaic patches in construction area, and conserving the river and riverside greenbelt, road shelterbelts and farmland shelterbelts to form a green corridor system. By establishing ecological infrastructure consisting of farmland, river wetlands, shelterbelts, local cultural landscape and their connections, a restrictive framework for land development and construction of Qin town can be formed [1].

Ecological Function Zoning. Ecological function zoning is based on the spatial differentiation of regional ecosystems, environmental sensitivity and ecological service functions. The region will be divided into different ecological function areas. It is the foundation of rational development and sustainable use of natural resources and the basis for ecological protection, ecological construction and environmental management [2]. According to the characteristics of the local ecological environment, the ecological function zoning in Qin town can be divided into the following three areas.

Agro-ecological areas are the supply of grain, vegetables, fruits, poultry, meat, eggs and other agricultural products. Green and organic agricultural production base should be actively developed to explore the ecological agriculture model.

Town ecological areas focus on construction area to increase public green space, and promote ecological residential area, industrial parks and eco-friendly industries.

River and wetlands areas refer to Fenghe wetlands. As the ecological sensitive area for water conservation, biodiversity protection and other ecological functions, the wetlands should be restored and rebuilt by using artificial methods, and the river corridor protection line should be controlled.

River Ecosystem Protection and Restoration. Fenghe River is a tributary of the Weihe River, so the destruction of Fenghe River will directly affects aquatic ecosystems and the ecological security of cities and towns in Weihe River Basin. As the important natural resources of Qin town, Fenghe River has both ecological value and cultural value. It is of great importance to protect and improve the environment of Fenghe River, for securing sustainable development and shaping the landscape of the town.

Establishment of River Ecological Corridor. First, the protection scope of river ecological corridor should be designated to strictly control the coastal construction (refer with: Fig. 4). Secondly, river protection zones are mainly for to wetland restoration, where embankment is covered with shrub and grass. In addition, outside of the river protection zones are buffer zones, where the shelterbelts should be built combined with a few small-scale facilities for leisure.

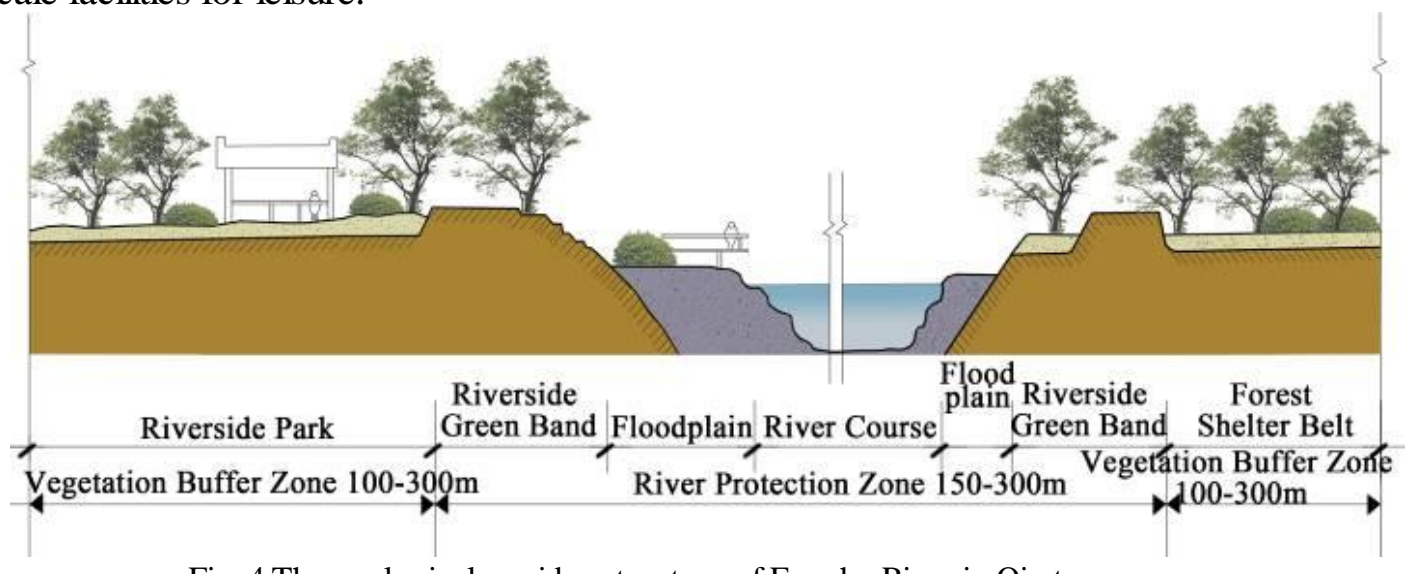

Fig. 4 The ecological corridor structure of Fenghe River in Qin town 
Restoration of Wetland. Wetland can be artificially rehabilitated by constructing slope wetlands in the floodplain, planting wetland vegetation, increasing sedimentation, and providing habitats. An ecosystem can be gradually restored referring to ecological succession principle by implementing classified and synchronized recovery of soil, plants and animals [3].

Improvement of Green Lands. Green lands connected with wetlands along Fenghe River should be planned and constructed to form the aquatic-terrestrial habitat. Facilities like viewing platform, rest kiosk, plank path and veranda should be set to provide bird watching and fishing for residents and visitors, thus to form a riparian ecological area with features of country landscape and wetland landscape.

Industry Guidance and Functional Layout. Strengthening the capacity of industry is an important way to achieve sustainable development in Qin town. The combination of self-sufficiency in agriculture, industrial ecology cycle and eco-development services will promotes the construction of new pattern urbanization.

Modern Agricultural Area. The development of modern agricultural area is mainly about urban modern agriculture, which promotes agricultural scale, industrialization and marketization process. Green economy should be advocated to form a new pattern of industrial structure consisting of agriculture, forestry, fruit, fish, flowers and eco-tourism. In addition, based on eco-agriculture and combined with sightseeing agriculture, leisure agriculture and experience agriculture, eco-tourism should be promoted. Development of vineyards, organic farms, citizen farms, leisure farms and other facilities can please more citizens and tourists with sightseeing farmland landscape as well as learning agricultural knowledge.

Commercial and Residential Area. Commercial and residential area consists of centralized resettlement area, quality community, administrative office, integrated commerce, health care, education, culture and sports, leisure and entertainment facilities. Relying on public transport and mixed land use, an energy-saving, low-carbon, green community should be built in every aspect: planning and layout, building design and technical measures. For the area of ancient town, the protection and restoration of historic relics such as ancient walls, gates, streets and buildings will pass on the tradition of spatial pattern. The vitality of the town will be enhanced by protection for both tangible and intangible cultural heritage.

Industrial Parks. There will be industrial park, science and technology park, creative industrial park and nursing home set up in industrial area, to build a modern industrial system with high-tech industries and modern services. Development of high-tech eco-industry and ecological park, focusing on eco-design, cleaner production, pollution prevention, efficient use of energy and enterprise cooperation, will help to transform the waste in production process into resources and reduce the emissions.

Riparian Recreation Area. It would be beneficial to develop Fenghe waterscape and start some leisure tourism projects by fully exploiting the natural and cultural tourism resources of the river. Tourism industry can be developed in combination with water restoration as well as recreation. Through construction of Fenghe landscape zone, ecological and landscape function should be strengthened to enhance the social and economic benefits in Qin town.

\section{Conclusion}

Ecology concept of sustainable development should be the top priority of new pattern urbanization construction in Qin town. Farmland landscape and river wetlands are important ecological resources in Qin town, while the layout of ancient town and historical relics are unique cultural resources. On the basis of restoration of natural landscapes combined with inheritance of culture and history, and protection of environment combined with development of eco-industries and eco-tourism, modern agriculture and modern industries should be developed to support the urbanization and promote harmonious development of urban \& rural society, economy and environment. 


\section{References}

[1] Kongjian Yu, Dihua Li, Luomeng Chao, Ten landscape strategies on construction of urban ecological infrastructure. Planners, 2001, 17 (6): 9-13.

[2] Liangqing Jia, Zhiyun Ouyang, Tongqian Zhao, Study on ecological function zoning. Journal of Ecology, 2005, 25 (2): 254-260.

[3] Yi Sun, Jianbin Guo, Puxing Dang, Theory and technology of wetland ecosystem restoration. Inner Mongolia Forestry Science and Technology, 2007, 33 (3):33-35. 